\title{
O CIRURGIÃO DIANTE DAS NOVAS TERAPIAS PARA O TRATAMENTO DO CÂNCER
}

\author{
THE SURGEON FACING NEW THERAPIES FOR CANCER TREATMENT
}

\author{
Paulo Cesar Fructuoso, TCBC-RJ ${ }^{1}$ \\ Accyoli Moreira Maia, TCBC-RJ ${ }^{2}$ \\ Italo Accetta, TCBC-RJ ${ }^{3}$
}

\section{INTRODUÇÃO}

Recentemente o mundo científico foi informado que novas drogas estavam mostrando expressiva eficácia na eliminação de tumores malignos induzidos experimentalmente em murinos. De acordo com os pesquisadores os medicamentos atuam interferindo com o mecanismo da angiogênese, fenômeno pelo qual os vasos sangüíneos neoformados, a partir de capilares situados próximos ao foco tumoral migram em direção à lesão promovendo grande aporte, não só de oxigênio como de outros nutrientes, além de fatores de crescimento das células carcinomatosas, proporcionando rápido aumento de sua população. $\mathrm{O}$ novo método difere radicalmente de tudo que se conhecia até então em termos de terapia antineoplásica, pois não atua diretamente na matriz carcinogênica e sim sobre as células endoteliais formadoras da neovascularização que nutre o neoplasma com os ingredientes necessários à sua multiplicação e disseminação.

A presente exposição tem por objetivo alertar a comunidade dos cirurgiões para a importância dos métodos recém divulgados, considerando a possibilidade de se obter em humanos os mesmos resultados consignados em animais, uma vez que, se confirmado estes fatos, certamente deverão transferir para o âmbito clínico o tratamento de grande número de neoplasias que requerem na atualidade procedimentos cirúrgicos como principal arma para combatê-las.

\section{O ESTADO DE TUMOR LATENTE}

Sabe-se que a progressão dos tumores sólidos é acompanhada pelo desenvolvimento de vigoroso processo de neovascularização ${ }^{1,2}$. Este fato é conhecido como angiogênese e é essencial, não somente para a evolução da neoplasia, mas também para a sua persistência e metastatização $0^{3,4,5}$. Por outro lado, o sistema vascular neoformado é mais atuante e contínuo do que aquele que se observa nos fenômenos fisiológicos similares descritos nos processos de cicatrização de feridas e formação da camada endometrial, entre outros. As células endoteliais estimuladas por fatores provenientes da massa blastomatosa são capazes de formar nova rede microvascular com velocidade de alongamento à razão de um milímetro por dia, mas curiosamente os mediadores químicos só exercem suas atividades junto aos capilares que estão nas proximidades do foco principal quando estes tenham uma população em torno de 106 células e ocupe um espaço de cerca de dois a três milímetros cúbicos ${ }^{2}$. Esta condição foi designada por Folkman como estado de latência ${ }^{1,2}$. Até esta fase que é de crescimento, as células componentes do clone neoplásico recebem, não só oxigênio e demais nutrientes, como também eliminam os seus catabólítos pelo processo de difusão intersticial. No estado de latência a população celular que compõe o blastoma apresenta um equilíbrio entre as suas frações

1. Mestrando de Cirurgia Gastroenterológica do Curso de Mestrado em Cirurgia Gastroenterológica do Departamento de Cirurgia Geral e Especializada da Faculdade de Medicina da UFF.

2. Coordenador do Curso de Mestrado em Cirurgia Gastroenterológica do Departamento de Cirurgia Geral e Especializada, da Faculdade de Medicina da UFF.

3. Vice-Coordenador do Curso de Mestrado em Cirurgia Gastroenterológica do Departamento de Cirurgia Geral e Especializada, da Faculdade de Medicina da UFF.

Recebido em 13/07/2000

Aceito para publicação em 22/03/2001 
proliferativas e apoptótica (mecanismo de eliminação celular por suicídio programado ou induzido). Nesta dimensão crítica, a lesão torna-se incapaz de crescer recebendo somente os nutrientes e eliminando os dejetos por meio de difusão intersticial. Este artifício gera uma autolimitação da sua expansão que só poderá ser ultrapassada se houver um novo aporte sangüíneo trazido pelos capilares recém formados (Figura 1).

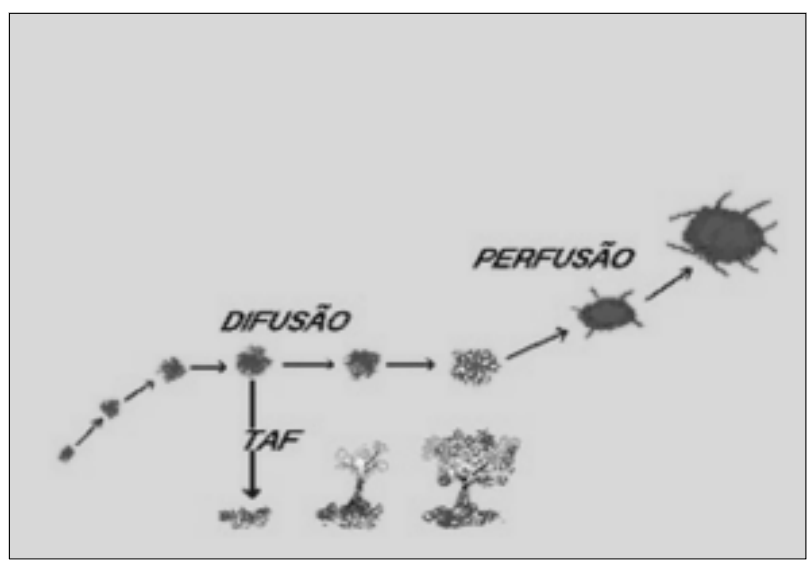

Figura 1 - Conceito da evolução dos tumores sólidos: Inicialmente crescem no espaço intersticial como pequenas células nutridas por difusão. Posteriormente o desenvolvimento requer vascularização direta e a neoplasia passa a ser mantida por perfusão. $O$ TAF pode ser o mediador da neovascularização. Adaptado de Folkman J: N Eng J Med 1971, 285: 1182-1186

\section{O FATOR DE ANGIOGÊNESE TUMORAL (TAF)}

Em 1971, Folkman ${ }^{1,2,6}$, isolou uma substância existente tanto em tumores de animais como da espécie humana, que era dotada de potente atividade de estimulação mitogênica sobre as células endoteliais, a qual denominou "Tumor Angiogenesis Factor"(TAF). Trata-se de uma proteína com peso molecular próximo de $100.000 \mathrm{kDa}$, contendo $25 \%$ de ácido ribonucleico; $50 \%$ de carboidratos e um componente lipídico que varia com a atividade angiogênica da molécula. A pesquisa da existência do TAF em tecidos orgânicos normais na ocasião foi negativa com exceção da placenta ${ }^{2-6}$.

As células endoteliais constituem em seu conjunto uma imensa camada de revestimento do sistema vascular ocupando uma área aproximada de $1.000 \mathrm{~m}^{2}$ no adulto de $70 \mathrm{~kg}^{7}$. Estas raramente proliferam, apresentando um tempo de duplicação de centenas de dias em função da fase G1 de seu ciclo celular ser extremamente longa ${ }^{8}$. Contudo, durante a angiogênese e em especial na neoformação vascular neoplásica, elas podem proliferar tão rapidamente quanto as progenitoras da medula óssea, que mostram um tempo de duplicação de poucos dias. Tal comportamento, diante de influxos, não somente de origens tumorais, mas também fisiológicos como os são os fatores de crescimento endotelial vascular(VGEF $)^{9-12}$, parecem variar de acordo com o órgão sede do tecido endotelial proliferante, o que sugere a existência de diferentes tipos de células endoteliais ${ }^{7}$.

Os mecanismos pelos quais as neoplasias transferem informações quimio-estimulantes às estruturas celulares normais localizadas nos capilares próximo ao sítio da lesão são desconhecidos, entretanto, sob tais impulsos estas saem do seu estado não proliferativo e experimentam grande atividade mitótica, originando uma poderosa rede microvascular que se insinua pelo interstício perineoplásico vazado pela ação de enzimas digestoras tumorais que facilitariam o acesso da neoformação vascular ao neoplasma (Figura 2) ${ }^{13}$.

Um novo aporte direto de oxigênio e nutrientes trazidos pela neovascularização à população celular do primórdio maligno promove a quebra do equilíbrio existente entre as frações proliferativa e apoptótica com franca vantagem para a primeira e conseqüente crescimento exuberante do tumor. Observa-se então que, enquanto o potencial metastático da neoplasia latente é muito baixo o do blastoma vascularizado é exuberante, pois estão abertos os caminhos através da circulação sangüínea e linfática.

$\mathrm{Na}$ verdade as comunidades celulares neoplásica e endotelial acabam por organizar um importante ecossistema integrado na intimidade do tumor, no qual os índices mitóticos das duas populações dependem essencialmente um do outro. Enquanto a neoplasia estimula o aumento e a multiplicação das células endoteliais via TAF, estas por sua vez não só transportam o oxigênio e nutrientes mas também fatores de crescimento e ainda facilitam a eliminação de metabólitos, atividade esta que contribui sobremaneira, embora de forma indireta, para a propagação da população blastomatosa. Tannock ${ }^{14,15}$ demonstrou que a probabilidade de uma célula carcinomatosa entrar em mitose diminui

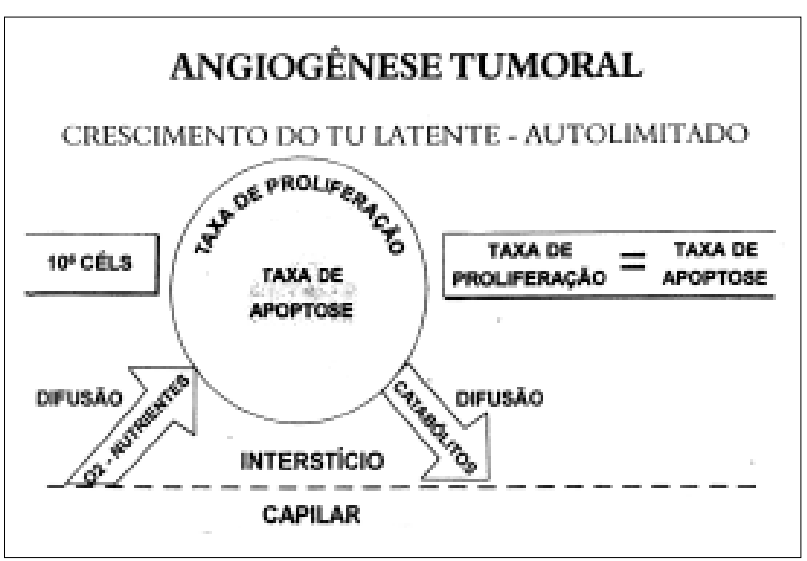

Figura 2 - Conceito de tumor latente: Em torno de 106 células ou 2 a $3 \mathrm{~mm}$ cúbicos de massa neoplásica ocorre um equilíbrio entre as frações proliferativa e apoptótica, autolimitando o crescimento neoplásico. A nutrição e a eliminação de catabólitos neste microssistema só ocorre por meio da difusão de partículas e gases através do interstício. 
com o aumento da distância entre esta e o capilar mais próximo. Então, mesmo depois que a vascularização tenha sido estabelecida, a eficiência da perfusão de nutrientes e metabólitos pode interferir com o crescimento da neoplasia Um exemplo deste fato pode ser observado com o câncer de mama em fêmeas de camundongos no qual o tempo de duplicação da célula endotelial é duas vezes mais rápido que o das células tumorais. Conseqüentemente, a diferença entre estas taxas de proliferação gera uma limitação indireta do desenvolvimento global do tumor.

Os estudos de Folkman demonstraram a existência de uma estratificação entre os diversos tipos de lesões malignas em correlação com a neovasculari-zação via TAF ${ }^{1,2}$. Os neoplasmas cerebrais parecem ser os que possuem maiores conexões neste aspecto, seguidos imediatamente pelos carcinomas, enquanto os sarcomas teriam menor dependência e, finalmente, os condrossarcomas apresentariam a mais pobre vinculação de todos. Os condroblastos, na realidade, demonstram capacidade de sobrevivência mesmo a grande distância dos capilares e por sua vez certos condrossarcomas alcançam volumes enormes, ainda que possuam capilares esparsos e as células endoteliais nestes vasos não estejam ativadas.

Em termos de terapia antiangiogênica, à luz dos conhecimentos atuais, aceita-se que o período mais vulnerável ao tratamento na evolução de um tumor sólido seria o curto intervalo de tempo que precede a neovascularização. Portanto, se o TAF puder ser bloqueado neste ponto, o crescimento neoplásico poderia ser contido em um diâmetro de dois a $3 \mathrm{~mm}$, ou seja, no estado de latência e conseqüentemente, com poder metastático mínimo. Assim, se a dependência endotelial hierárquica das lesões, for realmente comprovada também na espécie humana, não resta dúvida que a antiangiogênese seria um poderoso agente terapêutico para blastomas neurogênicos e carcinomas, sendo menos eficaz contra os sarcomas e inadequada no condrossarcoma.

\section{A INIBIÇÃO DO CRESCIMENTO METASTÁTICO PELO TUMOR PRIMÁRIO}

De há muito sabe-se que a remoção cirúrgica de alguns tumores primários é seguida pelo expressivo crescimento de suas metástases, principalmente em decorrência da vascularização dos focos secundários que se achava, de alguma forma, reprimida pela presença do neoplasma principal $^{16,17}$. Pelo menos três hipóteses foram avocadas para explicar o estranho fenômeno: 1) "A imunidade concomitante", que sugeria a existência de uma resposta imunológica induzida pela presença da lesão primitiva no hospedeiro; 2) A depleção de nutrientes em excesso pelo blastoma primário; 3) A produção de fatores antimitóticos pela neoplasia de origem com capacidade de inibir diretamente a difusão das células carcinomatosas em um sítio metastático. Nenhuma destas hipóteses conseguiu demonstrar a base molecular do mecanismo pelo qual o crescimento de um tumor pudesse suprimir o de outro.

Em 1993, O'Reilly ET AL. ${ }^{18}$ propuseram uma quarta hipótese: uma lesão primária, enquanto capaz de estimular a angiogênese em seu próprio leito tumoral poderia por outro lado frená-la concomitantemente quanto ao crescimento de suas metástases. Era uma idéia audaciosa que imediatamente levantava dúvidas sobre o motivo pelo qual um possível agente inibidor da atividade angiogênica das metástases não bloquearia também a vascularização do foco primitivo.

Em 1994 o mesmo O'Reilly ${ }^{19}$, descreveu a seqüência de uma molécula protéica idêntica a um fragmento central de plasminogênio humano, com peso de $38 \mathrm{kDa}$ ao qual denominou de angiostatina e que quando administrada de forma sistêmica a murinos portadores de tumores induzidos laboratorialmente bloqueava de forma efetiva o TAF e assim a neovascularização e o crescimento das metástases. A nova substância foi isolada de um polipeptídeo produzido pelo próprio carcinoma e sua atividade era detectável tanto no soro quanto na urina dos animais. A remoção do inóculo implantado previamente no tecido subcutâneo dos ratos era seguida por uma explosão, em tamanho, das lesões pulmonares que já se achavam presentes em dimensões reduzidas. Tal progressão era vertiginosa e elevava o peso do pulmão comprometido em até $400 \%$ em relação ao dos animais controle. A inibição da evolução metastática não mostrava dependência do sistema imune e era diretamente proporcional a grandeza do neoplasma primitivo. O novo agente antiangiogênico era produzido pela neoplasia, em quantidade que excedia o TAF e, enquanto este mostrava uma meia vida curta e atividade mais local a angiostatina possuía uma vida mais longa, o que lhe permitia alcançar áreas distantes e portanto uma ação sistêmica mais efetiva. Em resumo, o TAF, por suas características, era mais atuante no leito vascular primário e praticamente inócuo nos demais segmentos onde predominava a influência da angiostatina. Convém lembrar que a presença do tumor primário embora iniba o desenvolvimento de processos secundários, não impede que eles ocorram.

Em 1997, O’Reilly, usando estratégia similar a que o levou à descoberta da angiostatina, identificou uma segunda substância com características semelhantes à qual denominou endostatina, por ter sido isolada em metabólitos do hemangioendotelioma ${ }^{20}$. Esta, diferia da primeira por apresentar um peso molecular de $20 \mathrm{kDa}$ e uma estreita semilitude em sua seqüência de aminoácidos com um fragmento da extremidade da molécula do colágeno XVIII ao invés do plasminogênio. A administração deste novo inibidor da angiogênese a murinos provocou notável regressão das lesões primárias e secundárias até ao estado de latência, em decorrência, principalmente do maior crescimento da fração de células em apoptose. Nenhum efeito tóxico com a utilização deste bloqueador, mesmo em doses acima do necessário para promover a regressão tumoral foi observado. Fenômeno este também verificado com a angiostatina ${ }^{21,22}$. Outra constatação feita pelos pesquisadores e de grande importância foi que nenhuma das duas drogas induzia qualquer resistência medicamentosa, podendo portanto serem usadas com a mesma eficiência sempre que a lesão ultrapasse sua fase crítica de latência. Em relação à endostatina foi verificado que os hemangioendoteliomas não se mostraram sensíveis aos seus efeitos farmacológicos apesar dos mesmos terem origem nas células endoteliais normais. 


\section{ORIGEM DA ANGIOSTATINA}

Embora se saiba que a angiostatina pode ser obtida in vitro pela digestão do plasminogênio por uma elastase pancreática $^{18}$, o modo pelo qual é produzida pelo tumor não está devidamente esclarecido.

Um dos principais candidatos a esta função é o macrófago tumoral $^{13}$. Por outro lado, está perfeitamente estabelecido que tais células ocupam papel essencial na homeostase com participação expressiva na cicatrização de feridas, reações inflamatórias crônicas, restauração tecidual e defesa contra neoplasmas no hospedeiro. Freqüentemente nesses processos elas degradam as proteínas extracelulares através da produção de metaloproteinases que incluem a colagenase intersticial, a estromelisina, as colagenase tipo IV e finalmente as elastases ${ }^{23-26}$.

As metaloproteinases produzidas pelo macrófago são essenciais para a penetração tumoral na membrana basal dos tecidos e migração pelo interstício ${ }^{27}$. Ao que tudo indica existe uma maciça invasão do blastoma pelos macrófagos que chegam a constituir $60 \%$ do seu volume ${ }^{28,29}$. Dong em $1997^{12}$, parece ter elucidado, em parte, a origem da angiostatina neoplásica, in vivo, demonstrando que os macrófagos tumorais sob ação de citocinas das células carcinomatosas secretavam enzimas do grupo das metaloproteinases que com sua atuação digestora sobre o interstício não só ajudariam a expansão do processo invasor dos tecidos orgânicos normais, como também facilitariam a migração vascular em direção à lesão estimulada pelo TAF. Entre as enzimas estaria uma elastase com capacidade de clivar o plasminogênio do hospedeiro, dando origem então à angiostatina (Figura 3).

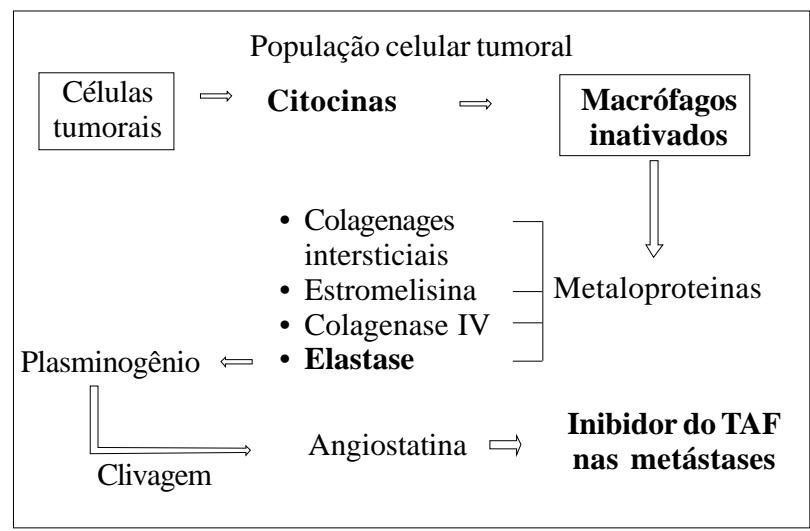

Figura 3 - Produção de angiostatina: citocinas de células carcinomatosas estimulam os macrófagos tumorais a produzir e secretar metaloproteinases entre as quais uma elastase capaz. de clivar o plasminogênio dando origem à angiostatina.

\section{DISCUSSÃO}

Ainda que a expectativa seja altamente promissora, convém lembrar que se deve manter a necessária e prudente cautela até que os resultados dos novos medicamentos aplicados às neoplasias humanas sejam divulgados. Por outro lado não se pode negar, e tudo faz crer, que um grande passo parece ter sido dado em direção à cura definitiva e irreversível dos tumores malignos, tanto que O'Reilly30, trabalhando com células tumorais humanas implantadas em murinos imunodeprimidos, para evitar rejeição imunológica, obteve regressão de $95 \%$ dos carcinomas mamários, $97 \%$ dos carcinomas de cólon e $100 \%$ dos carcinomas prostáticos, utilizando apenas a angiostatina. Os resultados foram tão animadores que mesmo neoplasmas cujos tamanhos correspondiam a até $2 \%$ do peso do animal, regrediam ao estado de lesão latente. A inibição da evolução foi alcançada, utilizando-se $10 \mathrm{mg} / \mathrm{kg} /$ dia e quanto maior a dose mais eficaz era o efeito. A angiostatina e a endostatina humana mostraram atividade superior às de origem murina, com relação a inibição da angiogênese e não foram constatados efeitos colaterais e/ou resistência medicamentosa nos ratos. Em se confirmando tais resultados no tratamento dos neoplasmas "in anima nobili", o referencial do enfoque terapêutico deverá ser inapelavelmente deslocado dos cirurgiões para os clínicos, isto porque tumores volumosos, que na atualidade exigem arriscadas e dispendiosas intervenções cirúrgicas realizadas por profissionais altamente qualificados através de intensos períodos de treinamento poderão estar totalmente ultrapassados no futuro, já que a possibilidade de reduzir grandes lesões para diâmetros em torno de $2 \mathrm{~mm}$ através do emprego de drogas à base de inibidores da angiogênese, certamente tornarão o tratamento dos tumores malignos, não só menos agressivos, mas também, menos onerosas tanto no que se refere aos estipêndios como também em relação ao risco cirúrgico. Mesmo as chamadas neoplasias líquidas, como a leucemia, que em seu conjunto representam cerca de $10 \%$ do total das doenças malignas que acometem o gênero humano, já não parecem estar a salvo deste novo arsenal terapêutico, pois trabalhos recentes, estão vislumbrando a possibilidade de bloqueio angiogênico das células leucêmicas no seu local de origem, ou seja, a medula óssea. Novas substâncias estão sendo testadas e entre elas destacam-se a trombospondina, a vasculostatina e os bloqueadores dos fatores de crescimento endotelial vascular (VEGF), o combrestatin A-4 etc. Entretanto, a par desta importante evolução no que se refere ao manejo dos neoplasmas malignos, uma grande incógnita permanece: o que fazer com a lesão residual, que embora latente, mantém ativo o potencial de crescimento e metastização desde que suspensos os bloqueadores da angiogênese. Poderão outros métodos de controle clínico como a imunoterapia ou mesmo a quimioterapia destruir esses resíduos tumorais? - Qualquer que seja a resposta é provável que o papel do cirurgião venha a se tornar cada vez mais minimizado no tratamento dos processos carcinomatosos.

As perspectivas são excitantes, mas só o tempo poderá nos dar esta resposta, contudo, a comunidade dos cirurgiões deve acompanhar a evolução da ciência e, não havendo outra alternativa, se curvar à evidência dos fatos, como já vem ocorrendo em outras eventualidades.

Assim, vivenciamos nesta virada do milênio, um período de grandes e extraordinárias transformações, inéditas na história da humanidade, possibilitadas pelo desenvolvimento acelerado das tecnologias de ponta e a cirurgia como arte não poderia permanecer incólume a estas magnânimas evoluções. 


\begin{abstract}
The cancer treatement has been subjected to substantial changes, mainly concerning clinical specialities. The advances on tumours study, especially related to genetics and molecular biology, greatly increased our understanding about many aspects of carcinogenesis, neoplasic growth and metastasizing process, untill now obscure. In this context, surgery seems to be attained its limits in trying to erradicate completely the disease, and although the great resections made, this aim has not been succeeded in many cases. New treatments are emerging each year and between the most promising we can highlight tumour angiogenesis chemical blocking agents, with highly promising experimental results. At the same time of the beginning of clinical researchs about these drugs, the authors present a review work, with the objective of presenting a general survey of the knowledge achieved about these recently discovered drugs in tumours control
\end{abstract}

Key words: Angiogenesis; Tumour angiogenesis blockers; Angiostatin ; Endostatin.

\section{REFERÊNCIAS}

1. Folkman J: Tumor Angiogenesis: Therapeutic Implications. N Engl J Med 1971; 285:1182-1186.

2. Folkman J: Anti-Angiogenesis: New Concept for Therapy of Solid Tumors. Ann Surg. 1972; 175:409-416.

3. Hori A, Sasada R, Matsutani E, et al: Suppression of Solid Tumor Growth by Immunoneutralizing Monoclonal Antibody against Human Basic Fibroblast Growth Factor Cancer Res. 1991; 51:6180-6184.

4. Kim KJ, Li B, Armani M, et al: Inhibition of Vascular Endothelial Growth Factor Induced Angiogenesis Suppresses Tumor Growth in vivo. Nature 1993; 362:841-844.

5. Milauer B, Shaver LK, Plate KH, et al: Glioblastoma Growth Inhibited in vivo by a Dominant - negative Flk 1 Mutant. Nature 1994; 367:841-844.

6. Folkman J: Tumor angiogensis and issue factor. Nature Med. 1996; 2:167-168.

7. Folkman J: Addressing tumor blood vessels. Nature Biotechnol. 1997; 15:510.

8. Denekamp J: Vascular attack as a therapeutic strategy for cancer: Cancer metastasis Ver. 1990; 9:267-282.

9. Joukov V, Kaipenen A, Jeltech M, et al: Vascular endothelial grow factors VEGF-B and VEGF-C, J Cell Physiol. 1997; 173:211-215.

10. Folkman J: Blood Vessel Formation: What is its Mollecular Basis? Cell 1996; 87:1153-1155.

11. Machein MR, Kullmer BL, Plate KH, et al: Vascular endothelial growth factor expression, vascular volume, and, capillary permeability in human brain tumors. Neurosurgery 1999; 44:732-740.

12. Dong HL, Hecht D, Song W, et al: Regional suppression of tumor growth by in vivo transfer of a cDNB encoding a secreted form of the extracellular domain of the filt-1 vascular endothelial growth factor receptor. Human Gene Ther. 1998; 9:823-833.

13. Dong Z, Kulmbr R, Yang X, et al: Macrophage derived metallelastase is responsible for the generation of angiostatin in Lewis lung carcinnoma. Cell 1997; 88:801810.

14. Tannock IF: The relation between cell proliferation and the vascular system in a transplanted mouse mamary tumor. Br J Cancer. 1968; 22:358-273.

15. Tannock IF: How tumor become angiogenic. Cancer Res. 1970; 2470-2476.

16. Sugarbaker EV, Thomthwait J, Ketcham AS: Inhibitory effect of a primary tumor metastasis. In: Progress in Cancer Research and Therapy - Day SB, Myers WPL, Stansly P, Garratin S and Lewis MG (EdS) - Raven Press, NY. 1997.
17. Clark WH, Jr., Elder DE, Guerry DIV, et al: Model predicting survival in stage I melanoma based on tumor progression. J Natl Cancer 1998; 81;1893-1904.

18. O'Reilly MS, Rosenthal R, Sge eh, et al:The suppression of tumor metastasis by a primary tumor. Forum 1993; 44:474-476

19. O'Reilly MS, Holmgren L, Shin Y, et al: Angiostatin: A novel angiogenesis inhibitor that mediates carcinoma. Cell 1994; 79:315-328.

20. O'Reilly MS, Michael S, Boehm T, et al: Endostatin: An endogenous inhibitor of angdiogenesis and tumor growth. Cell 1997; 88:277-285.

21. Sim BK, O'Reilly MS, Liang H, et al: A recombinant human angiostatin protein inhibits experimental primary and metastatic cancer. 1997; 57:1329-1334.

22. Hahnfeldt P, Panigra HY, Folkman J, et al: Tumor development under angiogenic signaling: a dynamical theory of tumor growth, treatment response, and postvascular dormancy. Cancer Res 1999; 59:4770-4775.

23. Shapiro SD, Kobayashi DK, Pentland AP, et al:Induction of macrophage metalloproteinases by extracellular matrix: evidence for enzyme and substrate-specific responses involving prostaglandin-dependent mechanism. J Biol Chem 1993; 268:8170-8175.

24. Xie B, Dong Z and Fidler IJ:Regulatory mechanism for the expression of type IV collagenasis gelatinases in murine macrophages. J Immunol 1994; 152;2637-3644.

25. Belaouaj A, Shipley JM, Kobayashi DK, et al: Human macrophage metalloelastase: Genomic organization, chromosomal location gene linkage, and tissue specifilc expression, J Biol Chem 1995; 270:14568-14575.

26. Werb Z and Gordon S: Elastase secretion by stimulated macrophagus:: Characterization and regulation. J Exp Med 1975; 142:361-377.

27. Shipley JM, Wesselschmidt RL, Kobayashi DK, et al: Metalloelastase is required for macrophage-mediated proteolysis and matrix invasion in mice. Proc Natl Acad Sci USA. 1996; 93:3942-3946.

28. Normann SJ: Macrophage infiltration and tumor progression. Cancer Metastasis Rev 1985; 4:277-291.

29. Withworth PW, Park CC, Esgro J, et al: Macrophages and cancer. Cancer Metastasis Rev. 1990; 8:319-351.

30. O'Reilly MS, Holmgren L, Chen C, et al: Angiostatin induces and sustains dormancy of human primary tumors in mice. Nature Med. 1996; 2:689-692.

Endereço para correspondência

Dr. Paulo Cesar Fructuoso

Rua Barão de Mesquita - 1085 apto: 204 - Grajaú

CEP: 20.540-002 - Rio de Janeiro - RJ

Fructuoso@bol.com.br 